\title{
Asymptomatic Hyperuricemia and Functional State of the Kidneys in Patients with Essential Arterial Hypertension and Concomitant Diabetes Mellitus Type 2
}

\author{
N. G. Virstyuk and A. O. Ikwuka
}

\section{ABSTRACT}

Introduction: The manuscript analyzes the frequency of asymptomatic hyperuricemia in association with disturbance of glucose and lipid metabolism, inflammatory process, and kidney changes in patients with essential arterial hypertension (EAH) and concomitant diabetes mellitus type 2 (DM2).

Aim: To determine the frequency of asymptomatic hyperuricemia in patients with EAH and concomitant DM2 and their effects on the main indicators of comorbid pathology.

Materials and methods: 120 patients (51 males and 69 females), aged 45-69 years with average age being $(58.2 \pm 5.7)$ years, were studied: 25 patients with treatment-compensated EAH, 1-2 degree, II stage (Group I); 25 patients with subcompensated DM2 (Group II) and 70 patients with treatment-compensated EAH, 1-2 degree, II stage and concomitant subcompensated DM2 (Group III). Control group consisted of 20 practically healthy volunteers $-8(40.0 \%)$ males and $12(60.0 \%)$ females, aged $(54.7 \pm 4.9)$ years. Groups were randomized according to age, sex, BMI, duration of EAH and DM2.

Results and discussion: Asymptomatic hyperuricemia were observed in $\mathbf{3 6 . 0} \%$ of group I patients, in $\mathbf{2 4 . 0} \%$ of group II patients and in $\mathbf{4 6 . 7 \%}$ of group III patients. Relevant correlations were found between uric acid level in the blood and such indicators as/for systolic blood pressure (SBP), glycated hemoglobin (HbA1C), dyslipidemia, inflammatory process, and kidney damage.

Conclusion: Asymptomatic hyperuricemia has a negative effect on the main indicators of comorbid pathology - in this case, EAH and concomitant DM2.

Keywords: asymptomatic, hyperuricemia, diabetes mellitus type 2, essential arterial hypertension, kidneys.

Published Online: June 30, 2021

ISSN: $2736-5476$

DOI: $10.24018 /$ ejclinicmed.2021.2.3.65

N. G. Virstyuk

Ivano-Frankivsk National Medical University, Ivano-Frankivsk, Ukraine. A. O. Ikwuka*

Ivano-Frankivsk National Medical University, Ivano-Frankivsk, Ukraine. (e-mail: aloysiussweet@yahoo.com)

\section{INTRODUCTION}

The prevalence of essential arterial hypertension (EAH) in patients with diabetes mellitus type 2 (DM2) is 2-3 times higher than in the general population, and $70 \%$ of patients with diabetes mellitus type 2 have high blood pressure, which significantly increases the risk of developing cardiovascular complications that deteriorate the prognosis and quality of life of patients and are the main causes of mortality [4], [10]. In EAH combined with DM2, the risk of developing renal failure increases by 15-20 times [1], [4], [11].

Diabetes mellitus and arterial hypertension remain two of the most common diseases in the world. Today, diabetes mellitus (DM) ranks third in the overall structure of morbidity and mortality after cardiovascular diseases and oncological diseases. According to the forecasts of the World Health Organization (WHO), its prevalence by 2030 will increase to 500 million people [1], [6], [10]. According to the $\mathrm{WHO}$, in recent decades the prevalence of DM in the countries of the world has increased by 1.5-2 times and ranges from an average of 1.5 to $3-4 \%$, and in developed countries of the world - up to 8-10\%. Every 10-15 years, the number of patients with DM doubles [6].

Uric acid (UA) is the ultimate purine metabolism product, its increase is associated with the development of gout [8]. Recently, the issue of the relationship between asymptomatic hyperuricemia and the development of cardiovascular pathology in the absence of gout has been actively discussed [5], [12]. Asymptomatic hyperuricemia is quite common in patients with essential arterial hypertension: it is found in $25-40 \%$ of patients with the first diagnosis of EAH, approximately in $80 \%$ of patients with severe EAH and in $50 \%$ of those who use diuretics [2], [7]. It has been proved that in the presence of hyperuricemia, arterial hypertension develops due to a decrease in renal 
blood flow followed by partial renal ischemia, which contributes to the activation of the renin-angiotensin system [3], [8], [12]. According to the results of a 5-year prospective study, the initial hyperuricemia determined the rate of progression of hypertensive kidney damage [3]. At the present time, hyperuricemia is considered as an independent predictor of the development and progression of chronic kidney disease (CKD) [9], [16].

\section{A. Aim}

To study the effect of asymptomatic hyperuricemia on the functional state of the kidneys in patients with essential arterial hypertension and concomitant diabetes mellitus type 2.

\section{MATERIALS AND MethodS}

120 patients (51 males and 69 females), aged 45-69 years with average age being (58.2 \pm 5.7$)$ years, were studied. Patients were divided into 3 groups: Group I included 25 patients with treatment-compensated essential arterial hypertension, 1-2 degree, II stage; Group II - 25 patients with subcompensated diabetes mellitus type 2 (glycated hemoglobin $\left(\mathrm{HbA}_{1} \mathrm{C}\right)$ - from 7.0 to $\left.11.0 \%\right)$; Group III - 70 patients with treatment-compensated essential arterial hypertension, 1-2 degree, II stage combined with subcompensated diabetes mellitus type 2 (glycated hemoglobin $\left(\mathrm{HbA}_{1} \mathrm{C}\right)-$ from 7.0 to $\left.11.0 \%\right)$. The control group consisted of 20 practically healthy volunteers made up of $8(40.0 \%)$ males and $12(60.0 \%)$ females, aged (54.7 \pm 4.9$)$ years. The studied groups were randomized according to age, sex, BMI, duration of EAH and DM2. Verification of diagnoses was carried out in accordance with the Order of the Ministry of Health of Ukraine No. 384 dated 24.05.2012 "On approval and implementation of medical and technological documents on standardization of medical care in arterial hypertension", "Updated and adapted clinical setting, based on evidence of "Arterial Hypertension" [4], Recommendations of the European Society of Hypertension and the European Society of Cardiologists (ESH/ESC, 2013), Order of the Ministry of Health of Ukraine No. 1118 dated 21.12.2012 "On approval and implementation of medical and technological documents for standardization of medical care in diabetes mellitus type 2", "Adapted clinical guidelines, based on the evidence of "Diabetes mellitus type 2" [1], Protocol of the American Association of Clinical Endocrinologists and the American College of Endocrinology [3] and the consultative conclusions of cardiologists and endocrinologists.

All patients underwent general clinical examination, monitoring of systolic blood pressure (SBP) and diastolic blood pressure (DBP). Features of glucose metabolism were evaluated by fasting blood glucose and postprandial glucose oxidase method, level of glycated hemoglobin $\left(\mathrm{HbA}_{1} \mathrm{C}\right)$; lipid metabolism - by the levels in blood of total cholesterol (TC), triglycerides (TG), low density lipoproteins (LDL) and high density lipoproteins (HDL). The level of uric acid in the blood was determined using fermentative colorimetric test. The determination of the levels of high-sensitivity Creactive protein (hs-CRP) and tumor necrosis factor alpha (TNF- $\alpha$ ) in serum was performed by immunofermentative method using "Diameb" (France) and ELISA Kit A-8756 "Diameb" (France) kits respectively; levels of neutrophil gelatinase-associated lipocalin (NGAL) in urine was determined using "Human Lipocalin-2 NGAL" ("Biovendor", Czech Republic) on a semiautomatic immunofermentative assay (IFA) analyzer ER-500 ("Sinnowa", China) with additional module - automatic microplate washer "SINNOWA W-600" (China) according to the instructions of manufacturers of test kits. The level of albuminuria was determined by rapid test strips ("PentaPhan", "LaChema"); quantitative determination of albumin levels in urine was performed by immunofermentation using the test system "Albumin-IFA" (LLC "Granula", Ukraine). The glomerular filtration rate (GFR) was calculated using the CKD-EPI formula [11]. Reduction of GFR from 89 to $60 \mathrm{ml} / \mathrm{min} / 1.73 \mathrm{~m}^{2}$ was considered as dysfunction of the kidneys - mild degree, from 59 to $30 \mathrm{ml} / \mathrm{min} / 1.73 \mathrm{~m}^{2}$ - moderate degree and from 29 to $15 \mathrm{ml} / \mathrm{min} / 1.73 \mathrm{~m}^{2}$ - severe degree, for 3 months or more with or without evidence of kidney damage corresponded to the definition of chronic kidney disease [1].

The study did not include patients diagnosed with gout, diabetes mellitus type 1 , decompensated diabetes mellitus type 2, severe arterial hypertension (third degree), primary kidney disease, other somatic pathology in active or decompensated forms, with reduced GFR less than $60 \mathrm{ml} / \mathrm{min} / 1.73 \mathrm{~m}^{2}$.

All studies were conducted in accordance with international and national policy documents: the Good Clinical Practice (GCP), the Declaration of Helsinki (DoH), the World Medical Association on the ethical principles of scientific medical research for human subjects, the Council of Europe Convention on Human Rights and Biomedicine, the Order of Ministry of Health of Ukraine No. 690 dated 23.09.2009 "On approval of the Procedure for conducting clinical trials of medicinal products and expertise materials of clinical trials and the Model regulations of Commissions on Ethical Issues", (in the edited Orders of the Ministry of Health of Ukraine No. 523 dated 12.07.2012 and No. 639 dated 01.10.2015).

Statistical analyses of results of the study were performed using Microsoft Excel computer program, using the methods of variation statistics, Student's t-test criteria and "Statistica 7.1 for Windows". The estimates of the statistical significance of the $\%$ difference was determined by the $\chi^{2}$ method. For the determination of the correlation between individual parameters, a paired factor correlation analysis was performed with the calculation of the Pearson correlation coefficient (r) and its reliability (p).

\section{RESUlTS OF THE RESEARCH AND THEIR DISCUSSION}

According to the results of anthropometric examination, visceral obesity was detected in $34(48.57 \%)$ patients of group III, compared with $7(28.0 \%)$ and $8(32.0 \%)$ patients in groups I and II respectively. BMI was found to be the highest in patients with essential arterial hypertension and diabetes mellitus type 2 of group III and exceeded this parameter in healthy volunteers by $33.32 \%$, in patients in groups I and II - by $19.48 \%$ and $15.78 \%$ respectively $(p<0.05)$. The ratio of OT/OC in patients of group III 
exceeded this parameter in healthy volunteers by $18.29 \%$ $(\mathrm{p}<0.05)$, in patients in groups I and II - by $11.49 \%$ and $7.78 \%$, respectively $(\mathrm{p}>0.05)$ (Table 1$)$.

Essential arterial hypertension was more pronounced in combined pathologies. In particular, systolic blood pressure (SBP) in group III patients exceeded that of healthy volunteers by $29.49 \%$, in groups I and II patients - by $10.45 \%$ and $19.89 \%$ ( $\mathrm{p}<0.05)$; also, diastolic blood pressure (DBP) in group III patients exceeded that of healthy volunteers and group II patients - by $22.19 \%$ and $14.79 \%$ respectively $(\mathrm{p}<0.05)$.

The results obtained indicate a more severe clinical course of essential arterial hypertension and concomitant diabetes mellitus type 2. In particular, fasting blood glucose in group III patients was $11.58 \%(\mathrm{p}<0.05)$ higher than that of group II patients and exceeded that of healthy volunteers and group II patients by 2.17 times and 1.97 times respectively $(\mathrm{p}<0.05)$. $\mathrm{HbA}_{1} \mathrm{C}$ in group III patients was higher by $14.99 \%(\mathrm{p}<0.05)$ compared with group II patients and exceeded that of healthy volunteers and group II patients by 1.93 times and 1.86 times respectively $(\mathrm{p}<0.05)$. arterial hypertension (group I), patients with subcompensated diabetes mellitus type 2 (group II) and, most especially in patients with treatment-compensated essential arterial hypertension combined with subcompensated diabetes mellitus type 2 (group III). In particular, the level of hs-CRP in the blood of group III patients exceeded that in groups I and II patients - by 2.53 times and 1.31 times respectively $(\mathrm{p}<0.05)$; level of TNF- $\alpha$ in group III patients exceeded that in groups I and II patients - by 2.26 times and 1.41 times respectively $(p<0.05)$, which confirms the strengthening of the systemic immunoinflammatory process in the presence of combined pathologies.

The level of uric acid was increased in the blood of all studied patients compared with the level in healthy volunteers $(\mathrm{p}<0.05)$. In particular, in group I patients, it was - (402.52 \pm 11.85$) \mu \mathrm{mol} / \mathrm{l}$; in Group II patients (385.24 \pm 9.60$) \mu \mathrm{mol} / \mathrm{l}$; the highest level was in group III patients $-(443.56 \pm 14.05) \quad \mu \mathrm{mol} / 1, \quad$ compared with $(287.60 \pm 6.53) \mu \mathrm{mol} / 1$ in healthy volunteers $(\mathrm{p}<0.05)$ (Fig. 1).
TABLE I: COMPARATIVE CHARACTERISTICS OF EXAMINED ANTHROPOMETRIC PARAMETERS IN PATIENTS WITH ESSENTIAL ARTERIAL HyPERTENSION AND CONCOMITANT DiabeTES MELlitus TyPe 2, M $\pm \mathrm{M}$

\begin{tabular}{|c|c|c|c|c|}
\hline Parameters & $\begin{array}{l}\text { Control } \\
\text { group, } \\
\mathrm{n}=20\end{array}$ & $\begin{array}{c}\text { Group I, } \\
n=25\end{array}$ & $\begin{array}{c}\text { Group II, } \\
n=25\end{array}$ & $\begin{array}{c}\text { Group III, } \\
\mathrm{n}=70\end{array}$ \\
\hline BMI, $\mathrm{kg} / \mathrm{m}^{2}$ & $25.39 \pm 0.67$ & $28.33 \pm 0.95 *$ & $29.24 \pm 1.26^{*}$ & $33.85 \pm 1.42 * \bullet$ \\
\hline $\mathrm{OT} / \mathrm{OC}$ & $0.82 \pm 0.01$ & $0.87 \pm 0.03 *$ & $0.90 \pm 0.03 *$ & $0.97 \pm 0.04 * \bullet$ \\
\hline $\mathrm{SBP}, \mathrm{mmHg}$ & $122.4 \pm 4.3$ & $143.5 \pm 5.9$ & $132.2 \pm 5.0$ & $158.5 \pm 7.3$ \\
\hline $\mathrm{DBP}, \mathrm{mmHg}$ & $77.5 \pm 2.6$ & $92.2 \pm 3.8$ & $82.5 \pm 3.2$ & $94.7 \pm 3.9$ \\
\hline $\begin{array}{l}\text { Fasting blood } \\
\text { glucose, } \\
\text { mmol/l }\end{array}$ & $4.26 \pm 0.18$ & $4.69 \pm 0.25$ & $8.32 \pm 0.40 *$ & $9.25 \pm 0.53 *_{\bullet}^{\circ}$ \\
\hline $\begin{array}{c}\mathrm{HbA}_{1} \mathrm{C}, \% \\
\text { Total }\end{array}$ & $462 \pm 0.25$ & $4.78 \pm 0.30$ & $7.74 \pm 0.38 *$ & $8.90 \pm 0.45^{* \bullet}$ \\
\hline $\begin{array}{c}\text { cholesterol, } \\
\mathrm{mmol} / \mathrm{l}\end{array}$ & $4.42 \pm 0.22$ & $5.52 \pm 0.27 *$ & $6.19 \pm 0.31 *$ & $6.85 \pm 0.37 * \bullet$ \\
\hline HDL, mmol/l & $1.65 \pm 0.13$ & $1.35 \pm 0.12 *$ & $1.22 \pm 0.10 *$ & $1.11 \pm 0.07 * \bullet$ \\
\hline $\mathrm{LDL}, \mathrm{mmol} / \mathrm{l}$ & $2.13 \pm 0.15$ & $2.68 \pm 0.17 *$ & $3.07 \pm 0.18 *$ & $3.54 \pm 0.23 *_{\bullet} \circ$ \\
\hline $\begin{array}{c}\text { Triglycerides, } \\
\mathrm{mmol} / \mathrm{l}\end{array}$ & $1.38 \pm 0.10$ & $1.82 \pm 0.13^{*}$ & $2.16 \pm 0.14 *$ & $2.43 \pm 0.17^{*} \bullet$ \\
\hline hs-CRP, mg/l & $0.78 \pm 0.04$ & $5.26 \pm 0.23 *$ & $10.15 \pm 0.48 *$ & $13.42 \pm 0.66 * \bullet$ \\
\hline TNF- $\alpha, p g / m l$ & $20.29 \pm 1.26$ & $28.43 \pm 1.72 *$ & $45.30 \pm 2.39 *$ & $64.29 \pm 3.70 * \bullet$ \\
\hline $\begin{array}{l}\text { - margin (sig } \\
\text { nd I. } \\
\text { - margin (sig }\end{array}$ & cance) of & $\begin{array}{l}\text { ence from c } \\
\text { erence bety }\end{array}$ & $\begin{array}{l}\text { ol group, } \mathrm{p} \\
\text { parameters }\end{array}$ & $\begin{array}{l}5 . \\
\text { groups III } \\
\text { groups III }\end{array}$ \\
\hline
\end{tabular}

According to the results of the laboratory examination, the atherogenic orientation of disorders of the blood's lipid spectrum in the studied patients was revealed, especially in essential arterial hypertension combined with diabetes mellitus type 2. In particular, in group III patients the total cholesterol level exceeded that of groups I and II patients by $24.09 \%$ and $10.66 \%$ respectively $(\mathrm{p}<0.05), \mathrm{TG}-$ by $33.52 \%$ and $12.5 \%$, respectively $(\mathrm{p}<0.05), \mathrm{LDL}-$ by $32.09 \%$ and 15.31 respectively $(\mathrm{p}<0.05)$, anti-atherogenic HDL level was lower - by $17.78 \%$ and $9.02 \%$, respectively $(\mathrm{p}<0.05)$.

The analysis of results of the conducted research revealed the increased level of hs-CRP and TNF- $\alpha$ in the blood of studied patients with treatment-compensated essential

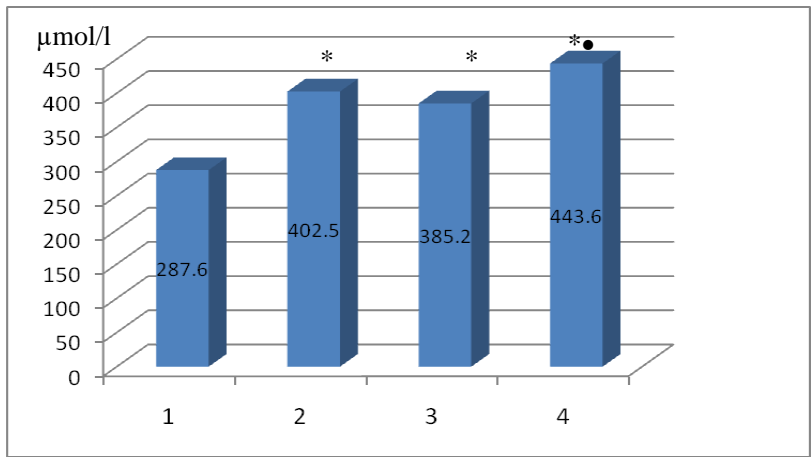

Fig. 1. Comparative characteristics of uric acid levels in the blood of patients with essential arterial hypertension and concomitant diabetes mellitus type 2 .

Notes: 1 - control group; 2 - groupI; 3 - group II; 4 - group III.

* - margin (significance) of difference from control group, $\mathrm{p}<0.05$

- - margin (significance) of difference between parameters in groups III and I.

${ }^{\circ}$ - margin (significance) of difference between parameters in groups III and II.

Asymptomatic hyperuricemia with increase in the level of uric acid in the blood by more than $410 \mu \mathrm{mol} / \mathrm{l}$ was observed in $36.0 \%$ of group I patients, in $24.0 \%$ of group II patients, and most often in $46.7 \%$ of group III patients.

Analysis of the results of the study revealed that changes in the kidneys were observed in patients of all groups according to the results of laboratory examinations and were more pronounced in group III patients, whereas no clinical manifestations of kidney damage were detected (Table II).

The average level of albuminuria in group III patients was 5.3 times higher than that in the control group $(\mathrm{p}<0.05)$ and in group I patients - by $2.91(\mathrm{p}<0.05)$.

According to results of the statistical analyses, some correlation coefficients were found between indicators such as hyperuricemia, SBP, glucose metabolism, lipid metabolism, inflammatory process, and kidney damage in the studied patients (Table III), which were most pronounced in group III patients with essential arterial hypertension and concomitant diabetes mellitus type 2 . 
TABLE II: COMPARATIVE CHARACTERISTICS OF CLINICAL AND LABORATORY PARAMETERS OF FUNCTIONAL STATE OF THE KIDNEYS IN PATIENTS WITH ESSENTIAL ARTERIAL HYPERTENSION AND CONCOMITANT DiABETES MELLITUS TYPE 2, M $\pm \mathrm{M}$

\begin{tabular}{|c|c|c|c|c|}
\hline Parameters & $\begin{array}{l}\text { Control } \\
\text { group, } \\
\mathrm{n}=20\end{array}$ & $\begin{array}{l}\text { Group I, } \\
\mathrm{n}=25\end{array}$ & $\begin{array}{c}\text { Group II, } \\
\mathrm{n}=25\end{array}$ & $\begin{array}{l}\text { Group III, } \\
\mathrm{n}=70\end{array}$ \\
\hline Albuminuria, mg/l & $17.95 \pm 0.60$ & $40.28 \pm 2.53 * \circ$ & $68.04 \pm 3.38 * \bullet$ & $92.47 \pm 6.05 * \bullet \circ$ \\
\hline $\mathrm{GFR}, \mathrm{ml} / \mathrm{min} / 1.73 \mathrm{~m}^{2}$ & $99.7 \pm 2.5$ & $84.1 \pm 2.8^{*}$ & $73.2 \pm 2.7^{*}$ & $64.6 \pm 3.2 * \bullet \circ$ \\
\hline Urea, $\mathrm{mmol} / \mathrm{l}$ & $5.53 \pm 0.37$ & $6.64 \pm 0.46^{*}$ & $7.78 \pm 0.52 *$ & $9.15 \pm 0.60 * \bullet \circ$ \\
\hline Serum creatinine, $\mathrm{mmol} / \mathrm{l}$ & $73.2 \pm 1.6$ & $87.2 \pm 2.2 *$ & $98.2 \pm 2.5^{*}$ & $108.2 \pm 3.0 * \bullet \circ$ \\
\hline Urine creatinine, mmol/l & $11.05 \pm 0.52$ & $10.96 \pm 0.58$ & $10.36 \pm 0.63$ & $9.85 \pm 0.75$ \\
\hline $\begin{array}{l}\text { Albumin/creatinine in urine, } \\
\qquad(\mathrm{mg} / \mathrm{l}) /(\mathrm{mmol} / \mathrm{l})\end{array}$ & $1.62 \pm 0.05$ & $3.65 \pm 0.18^{*}$ & $6.45 \pm 0.28 *$ & $9.35 \pm 0.46^{*} \bullet \circ$ \\
\hline NGAL in urine, $\mathrm{ng} / \mathrm{ml}$ & $7.32 \pm 0.36$ & $11.28 \pm 0.53 *$ & $22.36 \pm 1.05^{*}$ & $30.22 \pm 1.60 * \bullet \circ$ \\
\hline
\end{tabular}

Notes: $\mathrm{n}$ - number of subjects in a group; $*$ - margin (significance) of difference from control group, $\mathrm{p}<0.05 ; \bullet-$ margin $($ significance) of difference between parameters in groups III and I; ${ }^{\circ}-$ margin (significance) of difference between parameters in groups III and II.

TABLE III: CORRELATION COEFFICIENTS BETWEEN INDICATORS OF HYPERURICEMIA, BLOOD PRESSURE, GLUCOSE METABOLISM, LIPID METABolism, INFLAMmation AND KidNEy Damage IN PATIENTS With ESSENTIAL ARTERIAL HYPERTENSION AND CONCOMITANT DiABETES

\begin{tabular}{cccc}
\multicolumn{4}{c}{ MELLITUS TYPE 2 } \\
\hline Parameters & $\begin{array}{c}\text { Group I, } \\
\mathrm{n}=25\end{array}$ & $\begin{array}{c}\text { Group II, } \\
\mathrm{n}=25\end{array}$ & $\begin{array}{c}\text { Group III, } \\
\mathrm{n}=70\end{array}$ \\
\hline SBP, mmHg & $+0.52^{*}$ & $+0.35^{*}$ & $+0.59^{*}$ \\
$\mathrm{HbA} \mathrm{C}, \%$ & $+0.14^{*}$ & $+0.62^{*}$ & $+0.70^{*}$ \\
Total cholesterol, & $+0.33^{*}$ & $+0.47^{*}$ & $+0.57^{*}$ \\
$\mathrm{mmol} / \mathrm{l}$ & $+0.41^{*}$ & $+0.51^{*}$ & $+0.73^{*}$ \\
LDL, mmol/1 & $+0.29^{*}$ & $+0.45^{*}$ & $+0.62^{*}$ \\
Triglycerides, mmol/l & $+0.22^{*}$ & $+0.30^{*}$ & $+0.42^{*}$ \\
Albuminuria, $\mathrm{mg} / 1$ & $-0.17^{*}$ & $-0.37^{*}$ & $-0.51^{*}$ \\
GFR, ml/min/1.73m 2 & $+0.43^{*}$ & $+0.65^{*}$ & $+0.75^{*}$ \\
hs-CRP, mg/l & $+0.34^{*}$ & $+0.49^{*}$ & $+0.68^{*}$ \\
TNF- $\alpha, \mathrm{pg} / \mathrm{ml}$ & $+0.45^{*}$ & $+0.48^{*}$ & $+0.56^{*}$ \\
\hline NGAL in urine, $\mathrm{ng} / \mathrm{ml}$ & & &
\end{tabular}

$\mathrm{n}$ - number of patients in a group.

$*$ - correlation coefficientsp $<0.05$.

The results obtained, in our opinion, indicate the diverse pathogenetic effects of elevated uric acid levels in the blood with respect to $\mathrm{SBP}, \mathrm{HbA}_{1} \mathrm{C}$, dyslipidemia, albuminuria and impaired renal function (as observed in decreased GFR), which generally reflects the important role of uric acid in the development and progression of nephropathy.

Significant correlation coefficients were found between uric acid levels in the blood of group III patients and albuminuria $(\mathrm{r}=+0.42 ; \mathrm{p}<0.05)$, decreased GFR ( $\mathrm{r}=-0.51$; $\mathrm{p}<0.05)$ and increased level of NGAL in urine $(r=+0.56$; $\mathrm{p}<0.05$ ), which indicate in our opinion the adverse effect of asymptomatic hyperuricemia on the functional state of the kidneys in patients with EAH and concomitant DM2. Adverse effects of uric acid on the functional state of the kidneys may be due to intensification of the immunoinflammatory process and its association with arterial hypertension, dyslipidemia, and hyperglycemia. The results of experimental studies indicate that uric acid can promote the progression of chronic kidney disease by activating systemic inflammation [13]. A number of clinical studies have found a relationship between increased uric acid level and impaired renal function [14]-[16].

\section{CONCLUSIONS}

1. Asymptomatic hyperuricemia with increased level of uric acid in the blood by more than $410 \mu \mathrm{mol} / \mathrm{l}$ was seen in $36.0 \%$ of patients with treatment-compensated essential arterial hypertension, in $24.0 \%$ of patients with

subcompensated diabetes mellitus type 2, and most commonly in $46.7 \%$ of patients with treatment-compensated essential arterial hypertension and concomitant subcompensated diabetes mellitus type 2 .

2. Correlations between indicators of asymptomatic hyperuricemia, arterial hypertension, glucose metabolism, lipid metabolism, inflammatory process and kidney damage in the studied patients were found, which were most pronounced in patients with treatment-compensated essential arterial hypertension and concomitant subcompensated diabetes mellitus type 2 .

\section{PROSPECTS FOR FURTHER RESEARCH}

To find effective treatment regimens in patients with treatment-compensated essential arterial hypertension and concomitant subcompensated diabetes mellitus type 2 that will also reduce asymptomatic hyperuricemia in such patients.

\section{CONFLICT OF INTEREST}

The authors guarantee responsibility for everything published in this manuscript, as well as the absence of a conflict of interest and their own financial interest in performing this research and writing this manuscript.

\section{REFERENCES}

[1] MOH Ukraine (2012) Adapted clinical guidelines, based on evidence "Diabetes mellitus type 2" Order No. 1118 dated 21.12.2012 Available: http://www.moz.gov.ua/docfiles/dod1118_1_2012_.pdf.

[2] Tronko MD (2014) Reference key performance indicators in endocrinological service of Ukraine for 2013. Endocrinology 19(1):40.

[3] American Diabetes Association (ADA) (2017) Standards of medical care in diabetes. Diabetes care 40(1):75-98.

[4] MOH Ukraine (2012) Guidelines and clinical protocols of medical care "Arterial hypertension" Order No. 384 dated 24.05.2012. Page 107.

[5] Trifiro G, Sultana J, Giorgianni F, Ingrasciotta Y, Buemi M, Muscianisi M, et al (2014), Chronic kidney disease requiring healthcare services: a new approach to evaluate epidemiology of renal disease. BioMed Research International DOI: http://dx.doi.org/10.1155/2014/268362.

[6] Tashchuk VK, Vasek Obeid Al' Salama Muhamed (2016) Comorbidity, cardiovascular pathology and treatment of hyperuricemia - does allopurinol prevent its development? Bukovynsky medical bulletin 20(2): 209-212.

[7] Vassalle C, Mazzone A, Sabatino L, Carpeggiani C (2016) Uric acid for cardiovascular risk: Dr. Jekyll or Mr. Hide? Diseases 4(1) DOI: 10.3390/diseases4010012. 
[8] Zhdan VM, Kitura OYe, Kitura YeM, Babanina MYu, Tkachenko MV (2015) Hyperuricemia and arterial hypertension in general medical practice. Family medicine $4: 48-50$.

[9] Yakymenko YL (2014) Features of arterial hypertension combined with hyperuricemia in men. Ukr. med. journal 1(99): 1-2. Available online:http://www.umj.com.ua/article/70737/osobennosti-arterialnojgipertenzii-pri-sochetanii-s-giperurikemiej-u-muzhchin.

[10] Mishchenko LA (2016) Hyperuricemia and arterial hypertension - is there a connection? Ukrainian cardiology journal 3: 24-29.

[11] El Ridi R, Tallima HJ (2017) Physiological functions and pathogenic potential of uric acid: a review. Adv. Res. 8(5):487-493. DOI:10.1016/j.jare.2017.03.003.

[12] Johnson RJ, Nakagawa T, Jalal D, Sánchez-Lozada LG, Kang DH, Ritz E (2013) Uric acid and chronic kidney disease: which is chasing which? Nephrology Dialysis Transplantation 28(9): 2221-2228. DOI: 10.1093/ndt/gft029.
[13] Jalal DI, Chonchol M, Chen W, Targher G (2013) Uric acid as a target of therapy in CKD. American Journal of Kidney Diseases $61: 134-146$

[14] Goicoechea M, Garcia de Vinuesa S, Verdalles U, et al (2015) Allopurinol and progression of CKD and cardiovascular events: longterm follow-up of a randomized clinical trial. American Journal of Kidney Diseases 65:543-549.

[15] Kimura K, Hosoya T, Uchida S, et al (2018) Febuxostat therapy for patients with stage $3 \mathrm{CKD}$ and asymptomatic hyperuricemia: a randomized trial. American Journal of Kidney Diseases 72: 798-810.

[16] Mallamaci CZF (2018) Uric acid in chronic kidney disease: the quest for causality continues. Nephrology Dialysis Transplantation 33(2): 193-195. DOI: $10.1093 /$ ndt/gfx341. 